\title{
Factors associated with the frailty syndrome in elderly individuals living in the urban area ${ }^{1}$
}

\author{
Maycon Sousa Pegorari ${ }^{2}$ \\ Darlene Mara dos Santos Tavares ${ }^{3}$
}

\begin{abstract}
Objective: to identify the occurrence and factors associated with pre-frailty and frailty conditions among elderly individuals. Methods: this cross-sectional, observational and analytical household survey was conducted with 958 elderly individuals living in the urban area. The Brazilian version of the Functional Assessment Questionnaire and Multidimensional Scales (Depression, Katz and Lawton brief geriatric versions) were used, together with the Phenotype of Frailty developed by Fried. Descriptive analysis was performed along with a bivariate and multinomial logistic regression model $(p<0.05)$. Results: a total of $313(32.7 \%)$ non-frail elderly individuals were found in addition to 522 (55.4\%) pre-frail and 128 (12.8\%) frail individuals. Factors associated with pre-frailty and frailty, respectively, included: being 70 - 79 years old and 80 years old or older; using 1 - 4 medications and 5 or more; greater number of morbidities, functional disability for instrumental activities of daily life, and negative self-perception. The absence of a partner was associated with pre-frailty while hospitalization in the last year, functional disability for basic activities of daily life and indication of depression were associated with frailty. Conclusion: pre-frailty and frailty conditions presented a percentage higher than that reported by Brazilian studies and are associated with health-related variables. These variables can be prevented with interventions directed to the health of elderly individuals.
\end{abstract}

Descriptors: Frail Elderly; Urban Population; Odds Ratio; Health of the Elderly; Health Status.

\footnotetext{
${ }^{1}$ Paper extracted from master's thesis "Frailty syndrome: risk factors and quality of life of elderly people living in the urban area", presented to Universidade Federal do Triângulo Mineiro, Uberaba, MG, Brazil. Supported by Conselho Nacional de Desenvolvimento Científico e Tecnológico (CNPq), Brazil, process \# 301704/2012-0, and Fundação de Amparo à Pesquisa do Estado de Minas Gerais (FAPEMIG), Brazil, process \# APQ00866-12.

2 Doctoral student, Universidade Federal do Triângulo Mineiro, Uberaba, MG, Brazil. Scholarship holder from Fundação de Amparo à Pesquisa de Minas Gerais (FAPEMIG), Brazil.

${ }^{3} \mathrm{PhD}$, Associate Professor, Departamento de Enfermagem em Educação e Saúde Comunitária, Instituto de Ciências da Saúde, Universidade Federal do Triângulo Mineiro, Uberaba, MG, Brazil.
}

Corresponding Author:

Darlene Mara dos Santos Tavares

Universidade Federal do Triângulo Mineiro. Instituto de Ciências da Saúde

Av. Frei Paulino, 30

Bairro: Abadia

CEP: 38025-180, Uberaba, MG, Brasil

E-mail: darlenetavares@enfermagem.uftm.edu.br
Copyright (c) 2014 Revista Latino-Americana de Enfermagem This is an Open Access article distributed under the terms of the Creative Commons Attribution Non-Commercial License (CC BY-NC).

This license lets others distribute, remix, tweak, and build upon your work non-commercially, and although their new works must also acknowledge you and be non-commercial, they don't have to license their derivative works on the same terms. 


\section{Introduction}

Frailty among elderly individuals can be defined as a geriatric clinical syndrome that involves a physiological state of increased vulnerability to stressors that result in decreased physiological reserves and deregulation of multiple systems. It is supported by a triad of changes related to the aging process: sarcopenia, neuroendocrine deregulation, and immune system dysfunction ${ }^{(1-2)}$.

From the operational point of view, it is understood as a phenotype of frailty, proposed by Fried et al.(1), which includes five components: unintentional weight loss, self-reported fatigue and/or exhaustion, decreased muscle strength, slow walking speed, and low level of physical activity. Hence, the presence of one or two criteria characterizes the pre-frailty condition, while three or more criteria characterize frailty ${ }^{(1)}$.

Frailty is considered a predictor of adverse outcomes, such as: comorbidities, falls, the use of healthcare services, health conditions, institutionalization, impairment, negative impact on quality of life, mortality, and its prevalence is particularly relevant for the field of public health(1-3).

Brazilian and international studies have reported different prevalence rates, ranging from $6.9 \%$ to $40.6 \%$ among frail elderly individuals and $46.3 \%$ to $60.1 \%$ among pre-frail individuals. Associated factors include: being female, advanced age, low level of education and income; absence of a partner, living alone, negative health perception, functional disability, comorbidities, hospitalization, and indication of depression ${ }^{(1,4-8)}$.

In this sense, the frailty syndrome should be a target of investigations and interventions given its impact on elderly individuals, their families and the society as a whole(2). Despite recent initiatives ${ }^{(4-5,8)}$, there are few Brazilian studies assessing this condition and its associated factors taking into account pre-frail individuals. Differently from other studies conducted in Brazil addressing 65 years old or older individuals, this study's object of study focuses on 60 years old or older individuals. Deeper understanding regarding this syndrome can support the implementation of public policies and planning of strategic healthcare actions directed to this population and contribute to investigations in the Brazilian context to identify frail elderly individuals, considering loco-regional specificities.

This study's objective was to identify the occurrence and factors associated to the pre-frailty and frailty conditions among elderly individuals living in the urban area.

\section{Methods}

Household survey with analytical, observational and cross-sectional design conducted in 2012 with 958 elderly individuals living in the urban area of the city of Uberaba, MG, Brazil.

A representative sample of the elderly population living in urban Uberaba, MG, Brazil with 2,149 individuals was aimed at. The sampling computation considered $95 \%$ of confidence, $80 \%$ of test power, $4.0 \%$ of margin of error for interval estimates and an estimated proportion of $\pi=0.5$. Stratified proportional sampling was used, so that the various neighborhoods were considered strata.

The selection criteria included: being 60 years old or older, living in the urban area, not showing cognitive decline, being able to walk, being allowed to use an assistive device (e.g. cane, crutch, or walker), and providing written consent. Exclusion criteria were: not being located after three attempts, being hospitalized, or having neurological diseases that impeded the assessments.

A total of 958 elderly individuals met the inclusion criteria. Exclusion or losses included individuals who refused to participate (37); were hospitalized (14); had died (266); were not found after three consecutive visits (376); presented cognitive decline (160); other reasons (252); lived in the same household (64); and did not complete all the tests (22).

Previously trained undergraduate and graduate students collected the data. Interviews were held during a single meeting at the individuals' homes, divided into two stages: face-to-face semi-structured interview and anthropometric assessment plus physical performance tests. Before the interview, a cognitive assessment was conducted, using the translated version of an instrument validated in Brazil that considers education at the cut-off points for identifying cognitive deficit( ${ }^{(9)}$.

The dependent variable, frailty syndrome, was identified through five items, described as components of the frailty phenotype proposed by Fried et al.(1), as follows: (1) unintentional weight loss assessed by the question: "Have you unintentionally lost more than $4.5 \mathrm{~kg}$ or $5 \%$ of your body mass (that is, without diets or exercises) in the last year?"; (2) self-report of exhaustion and/or fatigue, measured through items 7 and 20 of the Brazilian version of the Depression Scale by CES-D. The individuals scoring 2 or 3 in any of the questions met the criterion for frailty in this item ${ }^{(10)}$; (3) decreased muscle strength, verified on the basis of grip strength, measured through a manual hydraulic dynamometer type JAMAR, model SAEHAN ${ }^{\circledR}$ SH5001 973, following the recommendations of the American 
Society of Hand Therapists. Three measures were obtained at an interval of one minute and are presented in kilogram/ strength (Kgf). The average value is considered, adopting the cut off points proposed by Fried et al.(1); (4) slow walking speed, in which time (in seconds) spent to walk a distance of 4.6 meters was considered. The individual walked a total distance of 8.6 meters while the two initial meters and the two final meters were not considered for the computation of the time spent walking. Three measures were taken and their average value was considered; this measure is presented in seconds. A professional stopwatch brand Vollo ${ }^{\circledR}$, model VL-1809 was used as the standard, together with the cut-off points proposed by Fried et al. ${ }^{(1)}$; and (5) low level of exercise verified by the long version of the International Physical Activity Questionnaire (IPAQ), adapted for elderly individuals ${ }^{(11)}$. The classification used for this component considered active those individuals who exercised 150 minutes or more weekly. Inactive individuals where considered those who spent 0 to 149 minutes per week with physical activities. Individuals who met three or more of these criteria were classified as frail, those who met one or two items were considered pre-frail, and those whose scores were negative in the tests were considered robust or non-frail(1).

The following were selected for the exploratory variables: (1) socio-economic and demographic characteristics: sex, race, age, marital status, housing, schooling, individual income measured through the Brazilian version of the Multidimensional Functional Assessment Questionnaire (BOMFAQ) ${ }^{(12)}$; (2) clinical health indicators: morbidities, number of regular medications, health perception verified through a question contained in $\mathrm{BOMFAQ}^{(12)}$ with alternative answers on a Likert scale: "In general, would you say your health is (very poor, poor, fair, good, excellent)?", self-reported smoking (yes, no) and hospitalization in the last year (yes, no); (3) indication of depression measured through the Geriatric Depression Scale (GDS$15)$, considering the cut-off point above $5^{(13)}$; and (4) functional disability was verified through self-report with the application of Katz's(14) scale for basic activities of daily living (BADL) and Lawton's scale for instrumental activities of daily living (IADL) ${ }^{(15)}$.

A spreadsheet was created to store data in Microsoft Office 2007 Excel $^{\circledR}$. Two people entered the collected data with dual input and the existence of inconsistencies was verified in two bases. After the necessary corrections, together with the original interview, the database was transferred to the Statistical Package for Social Sciences (SPSS) version 17.0 for analysis.
The categorical variables were analyzed through absolute frequencies and percentages and average and standard deviation were used for the numerical variables. In order to verify factors associated with pre-frailty and frailty, preliminary bivariate analysis was applied, using tests for measures of association (Coefficient Phi, Cramer's V and Kendall's tau-b) in contingence tables to verify tendencies among the exploratory variables (socio-demographic and economic, clinical, indication of depression, functional capacity and self-reported morbidities) with the dependent variable (level of frailty). The tests were considered significant when $p<0.10$.

According to the inclusion criteria $(p<0.10)$, the outcome variables were included in the multivariable regression model. In this stage, the number of selfreported morbidities variable was quantitative. Factors associated with pre-frailty and frailty were identified through multivariable analysis with odds ratio of prevalence through the multinomial logistic regression model (saturated model), considering a level of significance of $5 \%(p<0.05)$ and confidence interval $(\mathrm{CI})$ of $95 \%$.

The study received approval from the Institutional Review Board at the Federal University of Triângulo Mineiro (Protocol 2265/2012), in accordance with Brazilian Council of Health Resolution 196/96, and the subjects signed free and informed consent forms.

\section{Results}

The average age among the 958 participants was 73.77 years old $(s d= \pm 6.78)$, most were women $(64.4 \%)$, aged between 70 and 80 years old (50.4\%), Caucasian (56.6\%), from 1 to 4 years of schooling (55.5\%), and individual income of 1 time the minimum wage (51.2\%). A total of $12.8 \%(n=123)$ of the participants were frail, $54.5 \%$ were pre-frail $(n=522)$ and $32.7 \%(n=313)$ were not frail.

With regard to associated factors, the variables of the preliminary bivariate analysis submitted to multivariable analysis according to the criterion of inclusion $(p<0.10)$ were: being a woman $(p=0.039)$, aged 80 years old or older $(p<0.001)$, without a partner $(p=0.012)$, living alone $(p=0.084)$, illiteracy $(p<0.001)$, individual income up to 1 time the minimum wage, negative health perception $(p<0.001)$, using 5 or more medications $(p<0.001)$, hospitalization in the last year $(p<0.001)$, indication of depression $(p<0.001)$ dependence to perform BADL $(p<0.001)$ and IADL $(p<0.001)$, and 5 or more morbidities $(p<0.001)$, Tables 1 and 2 . 
Table 1 - Distribution of socio-economic and demographic variables among levels of frailty. Uberaba, MG, Brazil, 2012

\begin{tabular}{|c|c|c|c|c|c|c|c|c|c|}
\hline \multirow{2}{*}{ Variables } & \multicolumn{2}{|c|}{ Frailty } & \multicolumn{2}{|c|}{ Pre- frailty } & \multicolumn{2}{|c|}{ No frailty } & \multicolumn{2}{|c|}{ Total } & \multirow{2}{*}{$\mathbf{p}^{*}$} \\
\hline & $\mathbf{n}$ & $\%$ & $\mathbf{n}$ & $\%$ & $\mathbf{n}$ & $\%$ & $\mathbf{n}$ & $\%$ & \\
\hline Sex & & & & & & & & & 0.039 \\
\hline Male & 32 & 26.0 & 187 & 35.8 & 122 & 39.0 & 341 & 35.6 & \\
\hline Female & 91 & 74.0 & 335 & 64.2 & 191 & 61.0 & 617 & 64.4 & \\
\hline Age groups & & & & & & & & & $<0.001$ \\
\hline 60 - 70 years old & 23 & 18.7 & 128 & 24.5 & 127 & 40.6 & 278 & 29.0 & \\
\hline 70 아 80 years old & 51 & 41.5 & 286 & 54.8 & 146 & 46.6 & 483 & 50.4 & \\
\hline 80 years old or older & 49 & 39.8 & 108 & 20.7 & 40 & 12.8 & 197 & 20.6 & \\
\hline Race & & & & & & & & & 0.170 \\
\hline Caucasian & 81 & 65.9 & 293 & 56.1 & 167 & 53.4 & 541 & 56.5 & \\
\hline Afro descendant & 10 & 8.1 & 62 & 11.9 & 43 & 13.7 & 115 & 12.0 & \\
\hline Mixed & 27 & 22.0 & 150 & 28.7 & 94 & 30.0 & 271 & 28.3 & \\
\hline Asian & 2 & 1.6 & 14 & 2.7 & 7 & 2.2 & 23 & 2.4 & \\
\hline Indian & 3 & 2.4 & 2 & 0.4 & 2 & 0.6 & 7 & 0.7 & \\
\hline Marital status & & & & & & & & & 0.012 \\
\hline No partner & 69 & 56.1 & 321 & 61.5 & 163 & 52.1 & 553 & 57.7 & \\
\hline Partner & 54 & 43.9 & 201 & 38.5 & 150 & 47.9 & 405 & 42.3 & \\
\hline Housing & & & & & & & & & 0.084 \\
\hline Lives alone & 14 & 11.4 & 103 & 19.7 & 62 & 19.8 & 179 & 18.7 & \\
\hline Have company & 109 & 88.6 & 419 & 80.3 & 251 & 80.2 & 779 & 81.3 & \\
\hline Schooling & & & & & & & & & $<0.001$ \\
\hline Illiterate & 37 & 30.1 & 118 & 22.6 & 57 & 18.2 & 212 & 22.1 & \\
\hline 1$\} 4$ years & 70 & 56.9 & 293 & 56.1 & 169 & 54.0 & 532 & 55.5 & \\
\hline 5 or more & 16 & 13.0 & 111 & 21.3 & 87 & 27.8 & 214 & 22.3 & \\
\hline Individual income ${ }^{\dagger}$ & & & & & & & & & 0.009 \\
\hline No income & 10 & 8.1 & 37 & 7.1 & 26 & 8.3 & 73 & 7.6 & \\
\hline Up to 1 time the minimum wage & 73 & 59.3 & 278 & 53.5 & 138 & 44.2 & 489 & 51.2 & \\
\hline 1 - 3 times the minimum wage & 35 & 28.5 & 161 & 31.0 & 120 & 38.5 & 316 & 33.1 & \\
\hline $\begin{array}{l}\text { More than } 3 \text { times the minimum } \\
\text { wage }\end{array}$ & 5 & 4.1 & 44 & 8.5 & 28 & 9.0 & 77 & 8.1 & \\
\hline
\end{tabular}

*Coefficient Phi and Kendall's tau-b, $p<0.05$

†Minimum wage in 2012 in Brazil ( $R \$ 622.00 /$ month).

Table 2 - Distribution of clinical and health variables, functional ability and indication of depression. Uberaba, MG, Brazil, 2012.

\begin{tabular}{|c|c|c|c|c|c|c|c|c|c|}
\hline \multirow{2}{*}{ Variables } & \multicolumn{2}{|c|}{ Frailty } & \multicolumn{2}{|c|}{ Pre-frailty } & \multicolumn{2}{|c|}{ No frailty } & \multicolumn{2}{|c|}{ Total } & \multirow{2}{*}{$\mathbf{p}^{*}$} \\
\hline & $\mathbf{n}$ & $\%$ & $\mathbf{n}$ & $\%$ & $\mathbf{n}$ & $\%$ & $\mathbf{n}$ & $\%$ & \\
\hline Health perception $^{\dagger}$ & & & & & & & & & $<0.001$ \\
\hline Negative & 79 & 64.2 & 277 & 53.2 & 107 & 34.2 & 463 & 48.4 & \\
\hline Positive & 44 & 35.8 & 244 & 46.8 & 206 & 65.8 & 494 & 51.6 & \\
\hline Morbidities & & & & & & & & & $<0.001$ \\
\hline None & 0 & 0 & 7 & 1.3 & 14 & 4.5 & 21 & 2.2 & \\
\hline $1 \vdash 4$ & 32 & 26.0 & 184 & 35.2 & 154 & 49.2 & 370 & 38.6 & \\
\hline 5 or more & 91 & 74.0 & 331 & 63.4 & 145 & 46.3 & 567 & 59.2 & \\
\hline Use of medications & & & & & & & & & $<0.001$ \\
\hline None & 0 & 0 & 2 & 0.4 & 0 & 0 & 2 & 0.2 & \\
\hline $1 \vdash 4$ & 56 & 46.7 & 280 & 59.1 & 181 & 74.2 & 517 & 61.7 & \\
\hline 5 or more & 64 & 53.3 & 192 & 40.5 & 63 & 25.8 & 319 & 38.1 & \\
\hline Smoking & & & & & & & & & 0.786 \\
\hline Yes & 17 & 13.8 & 62 & 11.9 & 41 & 13.1 & 120 & 12.5 & \\
\hline No & 106 & 86.2 & 460 & 88.1 & 272 & 86.9 & 838 & 87.5 & \\
\hline Hospitalization in the last year & & & & & & & & & $<0.001$ \\
\hline Yes & 40 & 32.5 & 92 & 17.6 & 32 & 10.2 & 164 & 17.1 & \\
\hline
\end{tabular}


Table 2 - continuation

\begin{tabular}{|c|c|c|c|c|c|c|c|c|c|}
\hline \multirow{2}{*}{ Variables } & \multicolumn{2}{|c|}{ Frailty } & \multicolumn{2}{|c|}{ Pre-frailty } & \multicolumn{2}{|c|}{ No frailty } & \multicolumn{2}{|c|}{ Total } & \multirow{2}{*}{$\mathbf{p}^{*}$} \\
\hline & $\mathbf{n}$ & $\%$ & $\mathbf{n}$ & $\%$ & $\mathbf{n}$ & $\%$ & $\mathbf{n}$ & $\%$ & \\
\hline No & 83 & 67.5 & 430 & 82.4 & 281 & 89.8 & 794 & 82.9 & \\
\hline Basic Activities of daily life & & & & & & & & & $<0.001$ \\
\hline Dependent & 14 & 11.4 & 19 & 3.6 & 2 & 0.6 & 35 & 3.7 & \\
\hline Independent & 109 & 88.6 & 503 & 96.4 & 311 & 99.4 & 923 & 96.3 & \\
\hline Instrumental Activities of daily life & & & & & & & & & $<0.001$ \\
\hline Dependent & 114 & 92.7 & 374 & 71.6 & 180 & 57.5 & 668 & 69.7 & \\
\hline Independent & 9 & 7.3 & 148 & 28.4 & 133 & 42.5 & 290 & 30.3 & \\
\hline Indication of depression & & & & & & & & & $<0.001$ \\
\hline Yes & 55 & 44.7 & 137 & 26.2 & 50.0 & 16.0 & 242 & 25.3 & \\
\hline No & 68 & 55.3 & 385 & 73.8 & 263 & 84.0 & 716 & 74.7 & \\
\hline
\end{tabular}

*Cramer's V, Coefficient Phi and Kendall's tau-b, $p<0.05$

†Negative (very poor/poor/fair) and Positive (good/excellent).

The variables included in the multivariate model of multinomial logistic regression are presented in Table 3. Factors associated with pre-frailty include: being aged between 70 and 79 years old $(p<0.001)$ and 80 years old or older $(p<0.001)$, not having a partner $(p<0.001)$, using from 1 to 4 medications $(p=0.035)$ and 5 or more medications $(p=0.002)$, having a higher number of self-reported morbidities $(p=0.017)$, functional disability to perform IADL $(p<0.001)$, and having a negative health perception $(p=0.002)$. The following associated factors were found for the condition of frailty: being between 70 and 79 years old $(p=0.022)$ and 80 years old or older $(p<0.001)$, having been hospitalized in the last year $(p<0.001)$, taking from 1 to 4 medications $(p=0.041)$ and 5 or more medications $(p=0.006)$, number of selfreported morbidities $(p=0.002)$, functional disability to perform BADL $(p=0.009)$, functional disability for IADL $(p<0.001)$, indication of depression $(p=0.033)$, and negative health perception $(p=0.023)$, Table 3 .

Table 3 - Final model of the multinomial logistic regression for the variables associated with the frailty and pre-frailty condition. Uberaba, MG, Brazil, 2012

\begin{tabular}{|c|c|c|c|c|c|c|}
\hline \multirow{2}{*}{ Variables } & \multicolumn{3}{|c|}{ Pre-frailty } & \multicolumn{3}{|c|}{ Frailty } \\
\hline & $\mathrm{OR}^{*}$ & $95 \% \mathrm{Cl}^{\dagger}$ & $\mathbf{p}^{\ddagger}$ & $\mathrm{OR}^{*}$ & $95 \% \mathrm{Cl}^{\dagger}$ & $\mathbf{p}^{\ddagger}$ \\
\hline \multicolumn{7}{|l|}{ Age groups } \\
\hline 60 - 70 years old & \multicolumn{2}{|c|}{1} & & \multicolumn{2}{|c|}{1} & \\
\hline 70 - 80 years old & 2.09 & $1.48-2.96$ & $<0.001$ & 2.06 & $1.10-3.58$ & 0.022 \\
\hline 80 years old or older & 2.42 & $1.49-3.90$ & $<0.001$ & 5.98 & $2.96-12.09$ & $<0.001$ \\
\hline \multicolumn{7}{|l|}{ Sex } \\
\hline Male & \multicolumn{2}{|c|}{1} & & \multicolumn{2}{|c|}{1} & \\
\hline Female & 0.70 & $0.49-1.01$ & 0.055 & 1.18 & $0.65-2.13$ & 0.579 \\
\hline \multicolumn{7}{|l|}{ Marital Status } \\
\hline No partner & 1.84 & $1.27-2.67$ & 0.001 & 1.28 & $0.72-2.26$ & 0.392 \\
\hline Partner & \multicolumn{3}{|c|}{1} & \multicolumn{2}{|r|}{1} & \\
\hline \multicolumn{7}{|l|}{ Housing } \\
\hline Lives alone & \multicolumn{2}{|c|}{1} & & \multicolumn{2}{|c|}{1} & \\
\hline Has a companion & 0.88 & $0.58-1.36$ & 0.585 & 0.58 & $0.27-1.22$ & 0.155 \\
\hline \multicolumn{7}{|l|}{ Schooling } \\
\hline Illiterate & 0.95 & $0.58-1.56$ & 0.846 & 1.19 & $0.53-2.65$ & 0.665 \\
\hline 1$\} 4$ years & 0.96 & $0.65-1.42$ & 0.830 & 1.03 & $0.51-2.07$ & 0.925 \\
\hline 5 or more & \multicolumn{3}{|c|}{1} & \multicolumn{2}{|c|}{1} & \\
\hline \multicolumn{7}{|l|}{ Income ${ }^{\S}$} \\
\hline Yes & 1.52 & $0.66-3.45$ & 0.323 & 2.59 & $0.60-11.21$ & 0.202 \\
\hline Up to 1 time the minimum wage & 1.13 & $0.61-2.08$ & 0.688 & 2.06 & $0.65-6.51$ & 0.217 \\
\hline
\end{tabular}


Table 3 - continuation

\begin{tabular}{|c|c|c|c|c|c|c|}
\hline \multirow{2}{*}{ Variables } & \multicolumn{3}{|c|}{ Pre-frailty } & \multicolumn{3}{|c|}{ Frailty } \\
\hline & OR $^{*}$ & $95 \% \mathrm{Cl}^{\dagger}$ & $\mathbf{p}^{\ddagger}$ & OR $^{*}$ & $95 \% \mathrm{Cl}^{\dagger}$ & $\mathbf{p}^{\ddagger}$ \\
\hline 1 - 3 times the minimum wage & 0.79 & $0.43-1.45$ & 0.449 & 1.56 & $0.49-5.04$ & 0.448 \\
\hline $\begin{array}{l}\text { More than } 3 \text { times the minimum wage } \\
\text { and more }\end{array}$ & & 1 & & & 1 & \\
\hline \multicolumn{7}{|l|}{ Hospitalization } \\
\hline Yes & 1.45 & $0.92-2.30$ & 0.109 & 2.89 & $1.60-5.24$ & $<0.001$ \\
\hline No & & 1 & & & 1 & \\
\hline \multicolumn{7}{|l|}{ Use of medication } \\
\hline None & & 1 & & & 1 & \\
\hline $1 \vdash 4$ & 1.62 & $1.03-2.52$ & 0.035 & 3.67 & $1.05-12.78$ & 0.041 \\
\hline 5 or more & 2.36 & $1.36-4.10$ & 0.002 & 6.06 & $1.65-22.17$ & 0.006 \\
\hline Number of comorbidities & 1.08 & $1.01-1.15$ & 0.017 & 1.15 & $1.05-1.26$ & 0.002 \\
\hline \multicolumn{7}{|l|}{ Disability to perform BADL } \\
\hline Yes & 4.36 & $0.96-19.83$ & 0.057 & 8.68 & $1.73-43.51$ & 0.009 \\
\hline No & & 1 & & & 1 & \\
\hline \multicolumn{7}{|l|}{ Disability to perform IADL } \\
\hline Yes & 1.47 & $1.06-2.05$ & 0.020 & 5.31 & $2.46-11.41$ & $<0.001$ \\
\hline No & & 1 & & & 1 & \\
\hline \multicolumn{7}{|l|}{ Indication of depression } \\
\hline Yes & 1.07 & $0.71-1.61$ & 0.738 & 1.80 & $1.04-3.12$ & 0.033 \\
\hline No & & 1 & & & 1 & \\
\hline \multicolumn{7}{|l|}{ Health perception } \\
\hline Negative & 1.67 & $1.19-2.33$ & 0.002 & 1.82 & $1.08-3.05$ & 0.023 \\
\hline Positive & & 1 & & & 1 & \\
\hline
\end{tabular}

*Odds Ratio

+ Confidence interval

$\neq p<0.05 ; 1$ : Category of reference

sMinimum wage in 2012 in Brazil (R\$ 622.00/month)

\section{Discussion}

Elderly individuals in pre-frailty and frailty condition represent an expressive percentage of the individuals aged 60 years old or older addressed in this study; more than half of the participants were in the condition of prefrailty. Recent Brazilian studies show lower prevalence, such as those conducted by Rede FIBRA in Campinas, SP $(51.8 \% ; 9 \%)^{(4)}$ and in Belo Horizonte, MG (46.3\%; $8.7 \%)^{(5)}$. Other studies report higher prevalence in Santa Cruz, RN $(60.1 \% ; 17.1 \%)^{(8)}$ and the SABE study conducted in São Paulo, SP $(48.8 \% ; 40.6 \%)^{(6)}$. Likewise, studies conducted in the United States $(46.6 \% ; 6.9 \%)^{(1)}$ and in Mexico $(47 \% ; 15.7 \%)^{(7)}$ report different results.

The association of pre-frailty and frailty with being 70 to 79 years old or 80 years old or older corroborates the findings of both Brazilian ${ }^{(5,8)}$ and international studies $^{(1,6-7)}$. The influence of aging as a predisposition for the development of the frailty syndrome may be related to changes and decline taking place in multiple systems, due to the interaction of physiological mechanisms and pathological conditions ${ }^{(1)}$ with current and accumulated risks and functionality(4). Nonetheless, even though aging predisposes to the frailty syndrome, not all elderly individuals are frail(16) or pre-frail, suggesting there are common but not identical elements. Hence, it is believed that this syndrome presents more accentuated characteristics than those regarding the normative process of physiological aging(17).

The pre-frailty condition was associated with the absence of a partner; a similar result was found among Mexican pre-frail and frail elderly individuals(7). A longitudinal study conducted in São Paulo, SP reports female elderly individuals separated or divorced present mortality rates $82 \%$ and $35 \%$, respectively, higher than that observed among their married counterparts(18) In this sense, considering that the marital status is a component of the social support network of elderly individuals, we assume that, considering its complex interaction with clinical and social factors, the frailty syndrome sets in when there is rupture and/or absence of social ties ${ }^{(3,19)}$, considering a decline in physiological reserves $^{(1)}$ and the existence of stressful events or factors.

As opposed to other Brazilian and international studies $^{(1,5-6)}$, the variables: sex, housing, education and 
income were not associated with pre-frailty and frailty conditions. Other variables, such as being a woman, having low income and education, and living alone pose risks to the development of the frailty syndrome ${ }^{(1,6-7)}$, suggesting that disadvantages such as economic, educational and health deficits accumulated over the course of life may contribute to the problem(4).

In this study, the condition of frailty was associated with hospitalization in the last year, a result that disagrees with that reported by a study conducted in Belo Horizonte, MG, which found this association among frail and pre-frail elderly individuals ${ }^{(5)}$. Frail individuals experience decreased ability to respond to stressful situations, a vulnerability that predisposes them to chronic diseases, anorexia, sarcopenia, osteopenia, cognitive deficit and disabilities, which justify their greater susceptibility to adverse outcomes, such as hospitalization ${ }^{(1-2)}$.

Additionally, intervening hospitalizations are strongly associated with mortality in the transition between states of frailty. Hospital environments may compromise the functional conditions of elderly individuals, hindering recovery from frailty and prefrailty conditions. These findings show the need for actions to reduce hospitalizations due to evitable causes, preventive measures to avoid hospital complications(20), and the implementation of care protocols that take into account admission, procedures, surgeries, time of hospitalization, hospital discharge and post discharge.

The pre-frailty and frailty conditions remain associated with a greater use of medication, especially among those taking 5 or more medications. This finding was also reported by an international investigation in which polypharmacy was associated with increased prevalence and incidence of frailty among communitydwelling elderly individuals(21). Polypharmacy is considered a risk factor for frailty among the elderly(21), in which the overlap of multiple medications, indiscriminate use of medications, and associated side effects $^{(22)}$, may aggravate this condition. Moreover, the association between frailty and chronic diseases in this study indicates that the greater use of medications may reflect the manifestation of comorbidities.

This study's results include the association between pre-frailty and frailty and morbidities, corroborating Brazilian $^{(5,8)}$ and international(1-2,7) studies. Frailty and chronic diseases function as modulators of an individual's health, suggesting that understanding the presence or absence of these conditions may favor the representation of physiological reserves in old age ${ }^{(22)}$.
Frailty may enhance the development or progression of chronic diseases, possibly because of decreased levels of activity or the progression of other conditions that affect mechanisms responsible for homeostasis, such as inflammatory processes and sympathetic-parasympathetic balance(2). Additionally, frail elderly individuals experience increased vulnerability to stressful events, such as the manifestation of pathological processes due to low energetic reserves and/or their inefficient use, which result from a pathological response of the limited physiological reserve of this syndrome ${ }^{(22)}$.

Disability or dependence for the performance of instrumental activities of daily life was associated with the conditions of frailty and pre-frailty, however, disability to perform basic activities of daily life was only associated with frailty. Brazilian ${ }^{(5,8)}$ and international ${ }^{(1,7,23)}$ studies also report associations between frailty and disability to perform BADL and IADL. Despite distinctions in their theoretical conception(2) and confusion regarding the definition of frailty and disability due to the similarity between their adverse outcomes, frailty predicts disability among elderly individuals(23), which in turn, is seen as a outcome or contributing factor, potentially aggravating frailty and comorbidities ${ }^{(2)}$. Therefore, there is a need for care actions directed to the organization of healthcare services, family and society to cope with this scenario, in order to delay or alleviate functional decline in elderly individuals, taking into account frailty conditions, and specially pre-frailty, to promote an active aging process ${ }^{(5)}$.

Frail elderly individuals are $80 \%$ more likely to develop depressive symptoms. This association was also verified in other studies addressing pre-frail $(\mathrm{OR}=3.82$; $\mathrm{CI}=3.72-3,93)$ and frail $(\mathrm{OR}=11.23 ; \mathrm{CI}=10.89-11.58)$ Mexican individuals ${ }^{(7)}$, as well as pre-frail $(\mathrm{OR}=1.77$; $\mathrm{CI}=1.16-2.71)$ and frail $(\mathrm{OR}=2.62 ; \mathrm{CI}=1.23-7.02)$ Brazilians $^{(5)}$.

The complex and two-way causal nature between frailty and depression remains unknown. The presence of depressive symptoms may constitute a risk factor for this syndrome since changes in behavior, activity level, or social commitment may contribute to the decline of one's functional state and frailty. On the other hand, depressive symptoms may represent the early manifestation of frailty, worsening one's mood and depression due to the syndrome. Additionally, these conditions may overlap considerably, possibly indicating that somatic complaints are symptoms of diseases associated with the frailty syndrome(24). 
Pre-frail and frail elderly individuals present $67 \%$ and $82 \%$ more chances, respectively, of presenting a negative health perception, a result that agrees with that reported by other studies ${ }^{(6,8)}$. Given characteristics inherent to the condition of frailty and pre-frailty, such as decreased ability to respond to stressful conditions and greater susceptibility to adverse events (e.g. the progression of diseases), it is believed that these aspects justify such an association. On the other hand, it is possible that the perception of elderly individuals with regard to adverse events experienced over the course of life ${ }^{(8)}$, such as: personal experiences, goals, and mechanisms used to overcome disappointments and failures, may predispose to the frailty syndrome ${ }^{(8)}$.

\section{Conclusion}

The conditions of frailty presented a percentage higher than that reported by Brazilian studies and associated with health-related variables. The study revealed $313(32.7 \%)$ non-frail elderly individuals, 522 (55.4\%) pre-frail individuals and another 128 (12.8\%) frail ones. The factors associated with pre-frailty and frailty conditions, respectively, were: being $70+79$ years old and 80 years old or older; the use of 1 - 4 medications and 5 or more; higher number of morbidities, functional disability for instruments activities of daily living and negative perception of life. The absence of a partner was associated with pre-frailty, while hospitalization in the last year, functional disability to perform basic activities of daily life and indication of depression were associated with frailty.

The study's limitations included its cross-sectional design, which does not permit establishing a relationship of causality with the self-reported morbidities. The results of this investigation, however, contribute to deepen knowledge of the frailty syndrome among Brazilian elderly individuals and support the planning and implementation of interventions and care actions directed to this condition to prevent, revert or impede its progression.

\section{References}

1. Fried LP, Tangen CM, Walston J, Newman AB, Hirsch

C, Gottdiener J, et al. Frailty in older adults: evidence for a phenotype. J Gerontol A Biol Sci Med Sci. 2001;56(3):M146-56.

2. Fried LP, Ferrucci L, Darer J, Williamson JD, Anderson

G. Untangling the concepts of disability, frailty, and comorbidity: implications for improved targenting and care. J Gerontol A Biol Sci Med Sci. 2004;59(3):255-63. 3. Woo J, Goggins W, Sham A, Ho SC. Social determinants of frailty. Gerontology. 2005;51(6):402-8.

4. Neri AL, Yassuda MS, Araújo LF, Eulálio MC, Cabral BE, Siqueira MEC et al. Metodologia e perfil sociodemográfico, cognitivo e de fragilidade de idosos comunitários de sete cidades brasileiras: Estudo FIBRA. Cad Saúde Pública. 2013;29(4):778-92.

5. Vieira RA, Guerra RO, Giacomin KC, Vasconcelos KSS, Andrade ACS, Pereira LSM, et al. Prevalência de fragilidade e fatores associados em idosos comunitários de Belo Horizonte, Minas Gerais, Brasil: dados do estudo FIBRA. Cad Saúde Pública. 2013;29(8):1631-43.

6. Alvarado BE, Zunzunegui MV, Béland F, Bamvita JM. Life Course Social and Health Conditions Linked to Frailty in Latin American Older Men and Women. J Gerontol A Biol Sci Med Sci. 2008;63(12):1399-406.

7. Sánchez-García S, Sánchez-Arenas R, García-Peña C, Rosas-Carrasco O, Avila-Funes JA, Ruiz-Arregui $\mathrm{L}$, et al. Frailty among community-dwelling elderly Mexican people: prevalence and association with sociodemographic characteristics, health state and the use of health services. Geriatr Gerontol Int. 2013 Apr;14(2):395-402.

8. Sousa AC, Dias RC, Maciel AC, Guerra RO. Frailty syndrome and associated factors in community-dwelling elderly in Northeast Brazil. Arch Gerontol Geriatr. 2012;54(2):e95-e101.

9. Bertolucci PHF, Brucki SMD, Campacci SR, Juliano Y. Mini-exame do estado mental em uma população geral: impacto da escolaridade. Arq. Neuro-Psiquiatr. 1994;52(1):1-7.

10. Batistoni SST, Neri AL, Cupertino APFB. Validade da escala de depressão do Center for Epidemiological Studies entre idosos brasileiros. Rev Saúde Pública. 2007;41(4):598-605.

11. Mazo GH, Benedetti TRB. Adaptação do questionário internacional de atividade física para idosos. Rev Bras Cineantropom Desempenho Hum. 2010;12(6):480-4.

12. Ramos LR, Toniolto J, Cendoroglo MS, Garcia JT, Najas MS, Perracini M, et al. Two-year follow-up study of elderly residents in S. Paulo, Brazil: methodology and preliminary results. Rev. Saude Publica. 1998; 32(5):397-407.

13. Almeida OP, Almeida SA. Confiabilidade da versão brasileira da Escala de Depressão em Geriatria (GDS) versão reduzida. Arq Neuro-Psiquiatr. 1999;57(2):421-6. 14. Lino VTS, Pereira SRM, Camacho LAB, Ribeiro FST, Buksman S. Adaptação transcultural da Escala de 
Independência em Atividades de Vida Diária (Escala de Katz). Cad Saúde Pública. 2008;24(1):103-12.

15. Lopes SR, Virtuoso JS Júnior. Confiabilidade da versão brasileira da escala de atividades instrumentais da vida diária. Rev Bras Promoção Saúde. 2008;21:2906.

16. Bergman H, Ferrucci L, Guralnik J, Hogan DB, Hummel $S$, Karunananthan $S$, et al. Frailty: an emerging research and clinical paradigm-issues and controversies. J Gerontol A Biol Sci Med Sci. 2007;62(7):731-7.

17. Fulop T, Larbi A, Witkowski JM, McElhaney J, Loeb M, Mitnitski $A$, et al. Aging, frailty and age-related diseases. Biogerontology. 2010;11(5):547-63.

18. Gomes MMF, Turra CM, Fígoli MGB, Duarte YAO, Lebrão ML. Associação entre mortalidade e estado marital: uma análise para idosos residentes no Município de São Paulo, Brasil, Estudo SABE, 2000 e 2006. Cad Saúde Pública. 2013;29(3):566-78.

19. Amaral FLJS, Guerra RO, Nascimento AFF, Maciel ACC. Apoio social e síndrome da fragilidade em idosos residentes na comunidade. Cienc Saúde Coletiva. 2013;18(6):1835-46.

20. Gill TM, Gahbauer EA, Han L, Allore HG. The relationship between intervening hospitalizations and transitions between frailty states. J Gerontol A Biol Sci Med Sci. 2011; 66(11):1238-43.

21. Gnjidic D, Hilmer SN, Blyth FM, Naganathan V, Cumming RG, Handelsman DJ. High-risk prescribing and incidence of frailty among older community-dwelling men. Clin Pharmacol Ther. 2012;91(3):521-8.

22. Weiss CO. Frailty and chronic diseases in older adults. Clin Geriatr Med. 2011; 27(1):39-52.

23. Al Snih S, Graham JE, Ray LA, Samper-Ternent R, Markides KS, Ottenbacher $\mathrm{KJ}$. Frailty and incidence of activities of daily living disability among older Mexican Americans. J Rehabil Med. 2009; 41(11):892-7.

24. John PDS, Tyas SL, Montgomery PR. Depressive symptoms and Frailty. Int J Geriatr Psychiatry. $2013 ; 28(6): 607-14$. 